\title{
Operative fixation of type IV-VI acromioclavicular joint separation: an internal splint technique
}

\author{
Ritwik Ganguli* \\ Department of Orthopaedics, KPC Medical College and Hospital, Kolkata \\ Received: 16 May 2020 \\ Revised: 14 September 2020 \\ Accepted: 15 September 2020 \\ *Correspondence: \\ Dr. Ritwik Ganguli, \\ E-mail: drritwik86@gmail.com \\ Copyright: (c) the author(s), publisher and licensee Medip Academy. This is an open-access article distributed under \\ the terms of the Creative Commons Attribution Non-Commercial License, which permits unrestricted non-commercial \\ use, distribution, and reproduction in any medium, provided the original work is properly cited.
}

\begin{abstract}
Treatment of acromioclavicular (AC) joint separation is controversial. Rockwood type I, II, III AC joint injuries generally treated conservatively. In the literature there is various treatment options described for treating type IV - VI injuries with good and poor outcome but no single gold standard method. Rockwood type IV - VI AC joint separation treated with internal splint technique by passing Merselene tape through drill hole at lateral end clavicle, passing it under coracoid process and tied it after reducing vertical displacement of AC joint. Simultaneously horizontal displacement corrected and Merselene tape passed through drill hole of acromian process and tied. Endobuttn supports Merselene tape at superior aspect of clavicle. This study was conducted between April 2015 to March 2019 in KPC Medical College and hospital, Kolkata after taking ethical committee permission. 20 patients undergo surgical fixation of type IV-VI AC joint separation within 3 weeks of injury. Outcome of clinical and radiological parameter assessment was at 6,12, 24 weeks. Male female ratio was 7:3. Mean age 38.2 years, abduction was less than 100 degree in 2 patients at 6 months follow up due to inadequate compliance to physiotherapy. Other patients develop full Range of motion (ROM) and power of shoulder muscle 5/5. No cosmetic deformity except one painful scar. No postoperative displacement in alignment in Anteroposterior (AP) and axillary lateral view. This technique of interal spilint construct reduces need for rigid implant and biological procedure for acute $\mathrm{AC}$ joint dislocation though having excellent fixation strength, good reduction in both coronal and sagittal plane for proper healing of AC and Coracoclavicular (CC) ligaments.
\end{abstract}

Keywords: AC joint, Internal brace technique, CC ligament

\section{INTRODUCTION}

Acromioclavicular (AC) joint injury account for 40-50\% of athletic shoulder injury. This injury mainly results in contact sports, fall in outstretched hand or fall with arm in adducted position. ${ }^{1}$ This type of injury results in sprain of intraarticular AC ligament and extraarticular coracoclavicular (CC) ligament. Vast majority of AC joint injuries (Rockwood I-III) can be treated with conservative management with good result. ${ }^{3,7}$ But injuries with high velocity trauma result in severe type of injury (Rockwood IV-VI) where operation is treatment is of choice of the young active patients. $^{2}$ There are several operative modalities described in literature including open and arthroscopic technique to tackle these injuries. ${ }^{8}$ Still now no single procedure found to be gold standard. Previously these injuries are treated with Bosworth screw and hook plate but these have numerous disadvantages like implant breakage, hardware migration, osteolysis of acromian 11 and distal end of clavicle, need for implant removal, and recurrence of deformity after hardware removal, persistent pain and so on. ${ }^{4,5}$ After that anatomical reconstruction in the form of biological fixation came with good results. ${ }^{6}$ But iatrogenic fracture of distal clavicle in Indian population with thin clavicle has been reported. 
Internal bracing is basically open reduction of AC joints and internal fixation with high strength suture like Mersilene tape (Johnson and Johnson) or fibre ware between coracoid process, distal clavicle and acromian process and supported over the top of distal clavicle with Endobutton. ${ }^{12}$

Patients can be given early range of motion (ROM) exercise as the fixation strength is very good. This result is less chance of stiffness, pain, early return to activities and good muscle power and coordination.

\section{CASE SERIES}

The proposed study was conducted in the Department Orthopaedics KPC Medical College and Hospital, Kolkata during period of April 2015 to March 2019.

\section{Sample design}

Patient with AC joint injury with Rockwood type IV-VI within 3 weeks since injury.

\section{Study design}

The study design was prospective study.

\section{Parameters studied}

Following parameters were studied: sequential follow up with clinical examination and radiographic study, ROM of shoulder and DASH (Disabilities of arm, shoulder, hand) score.

\section{Study tools}

Following study tools were included in the study-patient informed consent form, vase sheets for relevant history and clinical examinations, goniometer for ROM and roentgenography, DASH score.

\section{Procedure}

The ethical approval and patient consent was taken before operative intervention.

Type of AC joint separation was determined on the basis of radiographs (anteroposterior (AP) shoulder, AP stress view axillary lateral) and physical examination. Operation was done by regional or general anesthesia. Patient was put on a beech chair position.

Lateral end of clavicle, acromian process, and AC joint capsule dissected after incising platysma and subcutaneous tissue, anterior fibers of deltoid erased from lateral end clavicle and acromian. Coracoid process identified by tracing coracoacromial ligament. Torn $\mathrm{CC}$ ligament visualized. Dissection done all around medial, lateral and undersurface of coracoid. Right angle forceps inserted from lateral to medial side of coracoid beneath its base. 3.5 $\mathrm{mm}$ drill bit used to drill a hole $2.5 \mathrm{~cm}$ from lateral end of clavicle.

6-7 cm incision over AC joint from lateral end of tip of acromian process to the level of coracoid.

$5 \mathrm{~mm}$ Mersilene tape with Endobutton passed through the lateral end clavicle.

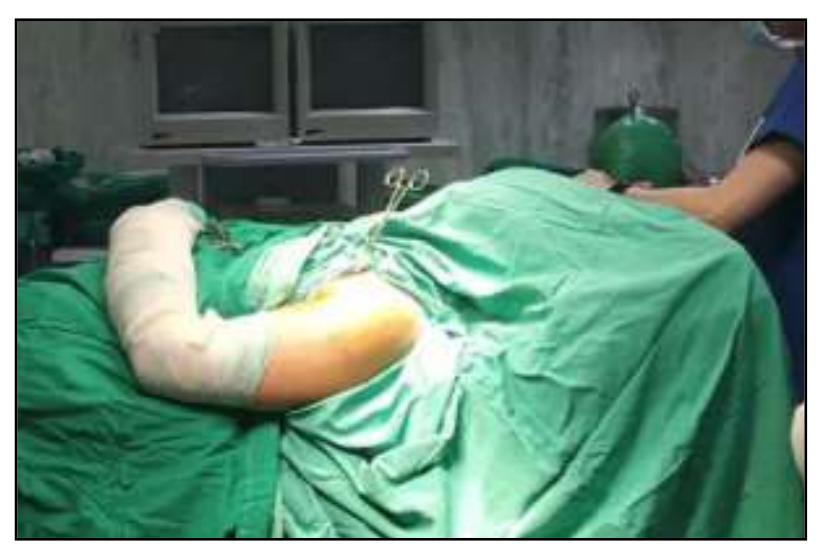

Figure 1: 6-7 cm incision over AC joint from lateral end.

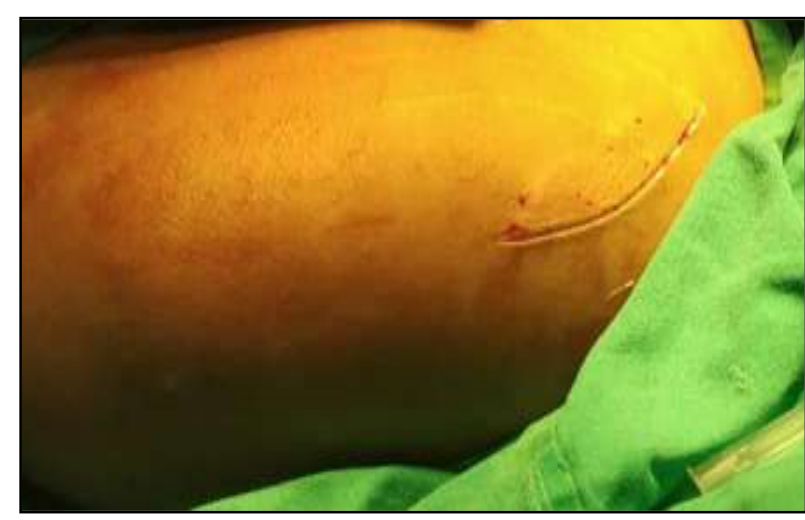

Figure 2: Lateral end of clavicle, acromian process, and $\mathrm{AC}$ joint capsule
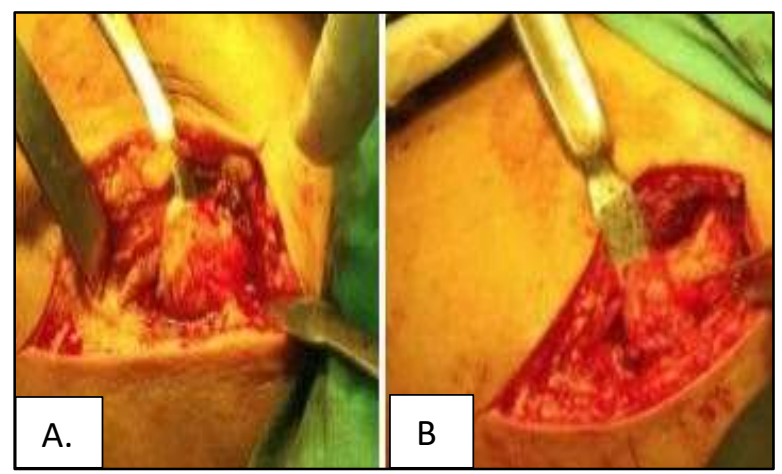

Figure 3: $5 \mathrm{~mm}$ Mersilene tape with Endobutton passed through the lateral end clavicle.

$3.5 \mathrm{~mm}$ drill hole made at lateral end acromian. Merselene tape passed through the drill hole and tied which supports 
AP stability. Some patients require temporary percutaneous $\mathrm{k}$ wire fixation of $\mathrm{AC}$ joint which removed after 2 weeks. Wound closed in layers after checking stability of fixation. Postoperative arm kept in sling.

Postoperative X-rays were taken in every patient.

\section{Rehabilitation}

Passive ROM with arm sling for 3 weeks, active ROM and strengthening exercise started after 3 weeks and normal activity after 3 to 5 months.

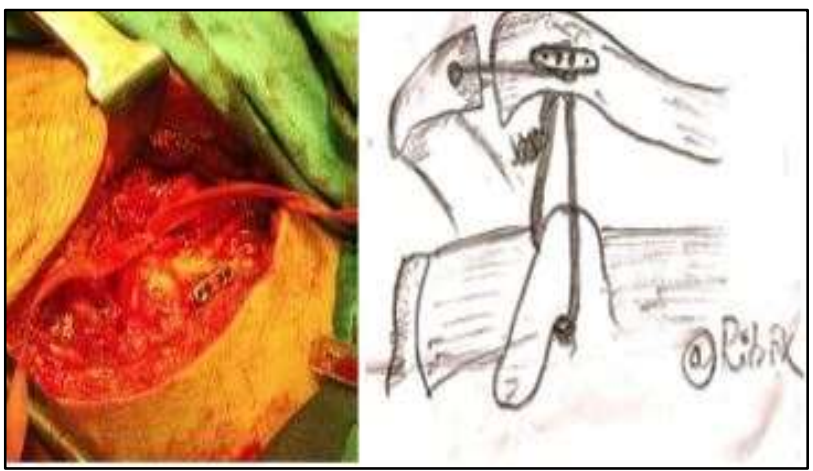

Figure 4: $3.5 \mathrm{~mm}$ drill hole made at lateral end acromian.

\section{Some cases in case series}

Case no. 1

25 years old gentleman history of fall 3 days before during playing football. X-ray shows Rockwood type V AC joint separation. Patient is now more than 3 years follow up and doing all sports activities with full ROM of shoulder.

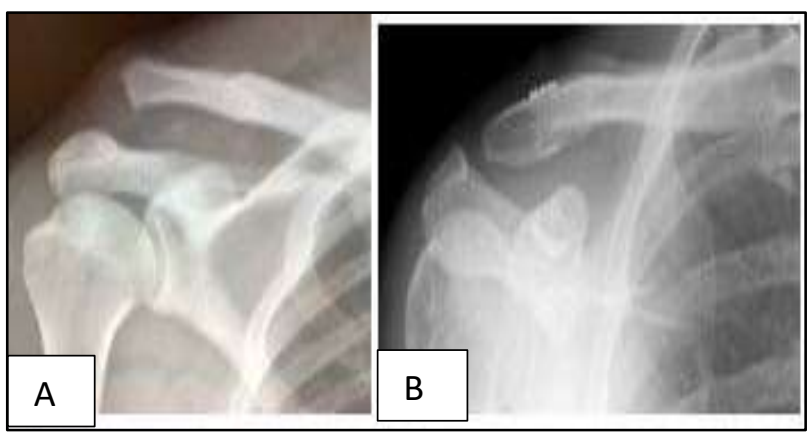

Figure 5: (A) Pre-operative X-ray, (B) post-operative X-ray.

Case no. 3

19 years young male athlete history of fall during playing foot fall. Pain, swelling and deformity of left AC joint area. X-ray rockwood type V AC joint separation. Operated next day. Patient now having more than two and half months follow-up with excellent functional outcome and return to sports after 4 months of trauma.

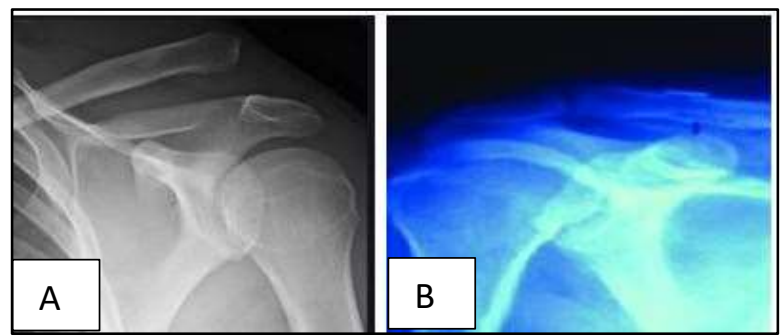

Figure 6: (A) Pre-operative X-ray, (B) post-operative X-ray.

Case no. 5

42 years male with sedentary lifestyle history of fall 2 days before. Pain and prominence of AC joint. Operated after 3 days. Postoperative period was uneventful. Lost follow up after 6 weeks.

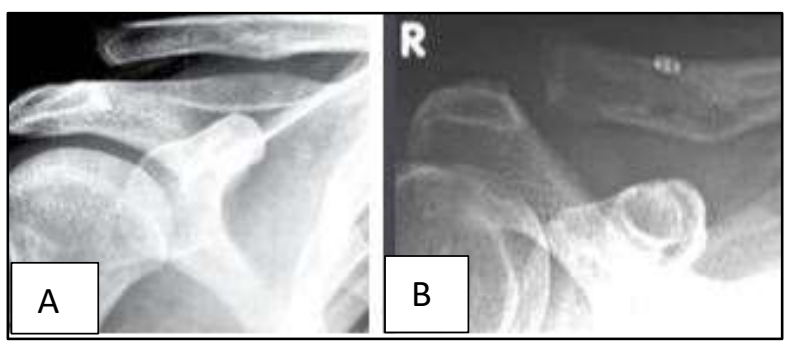

Figure 7: (A) Pre-operative X-ray, (B) post-operative X-ray.

Case no. 7

40 years female history of domestic fall 2 days before. History of diabetes and chronic liver disease. Operated 6 days post trauma. X-ray shows superior migration of distal clavicle. Postoperative 2 years follow up, patient having good ROM but mild pain around AC joint.

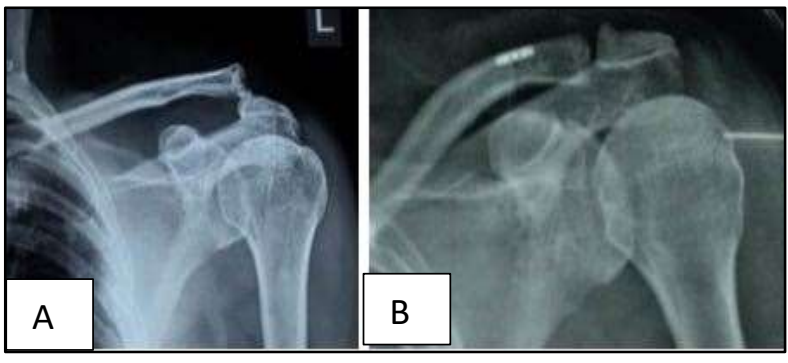

Figure 8: (A) Pre-operative X-ray, (B) post-operative X-ray.

\section{Case no. 9}

55 years male history of domestic fall on right shoulder. Diabetic on medication. Superior migration of lateral end 
clavicle operated next day with end button loop fixation. After 3rd post-operative visit at 6 weeks patient lost follow up. Patient shows good recovery with time.

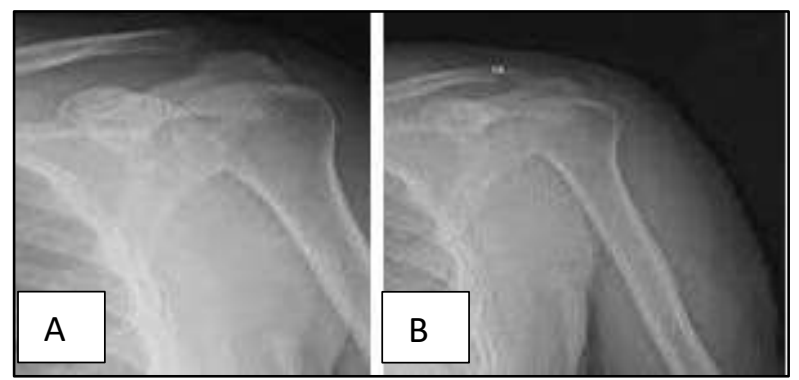

Figure 9: (A) Pre-operative X-ray, (B) post-operative X-ray.

\section{Case no. 11}

19 years male history of sports injury. Type 5 dislocation of AC joint. Operated same day. By 3 months patient shows full ROM of shoulder and joined sports activities after 3 months.

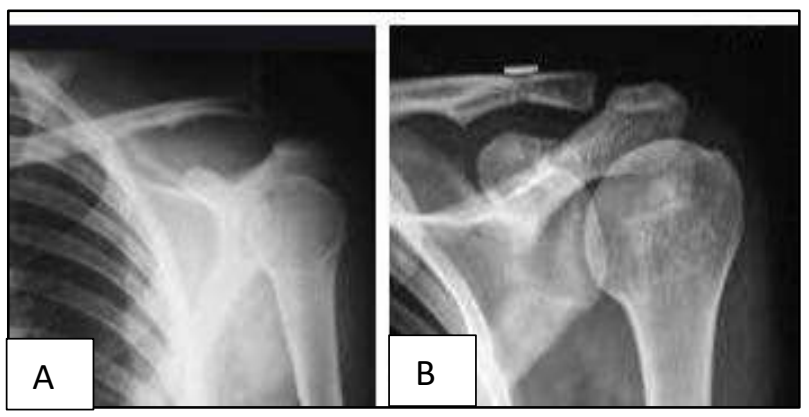

Figure 10: (A) pre-operative X-ray. 10B, postoperative $\mathrm{X}$-ray.

Case no. 13

42 years male fall on his left shoulder. Rockwood type 4 dislocation of $\mathrm{AC}$ joint. Reduction and fixation done in same day. 6 months follow up shows good ROM, muscle strength.

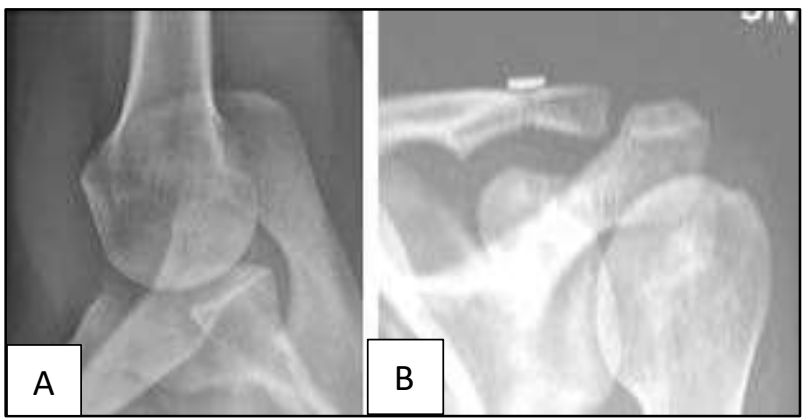

Figure 11: (A) Pre-operative X-ray, (B) post-operative X-ray.

\section{Case no. 15}

35 years old male history of Road traffic accident (RTA) having multiple fracture and $\mathrm{AC}$ joint dislocation. AC joint was operated after initial stabilization and fixation of long bone injuries. AC joint operated 7 days post trauma. Patient having 9 months of follow up and shows good pain free ROM of shoulder.

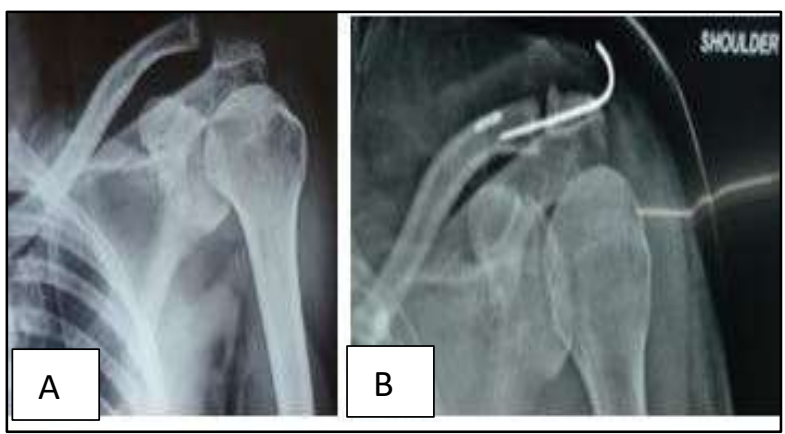

Figure 12: (A) Pre-operative X-ray, (B) post-operative X-ray.

\section{DISCUSSION}

20 patients with Rockwood type IV-VI included in the study. Mean age 38.2 years (22-56 years). The male to female ratio was 7:3. Only 2 patients were hypertensive ad one patient was diabetic at time of treatment. All patients operated within 3 weeks since injury (average 5.6 days). Injured right to left side ratio was 13:7. No patients received perioperative blood transfusion. All wounds were healthy except for the diabetic patient. Stitch removal done at 14 th day post-operative.

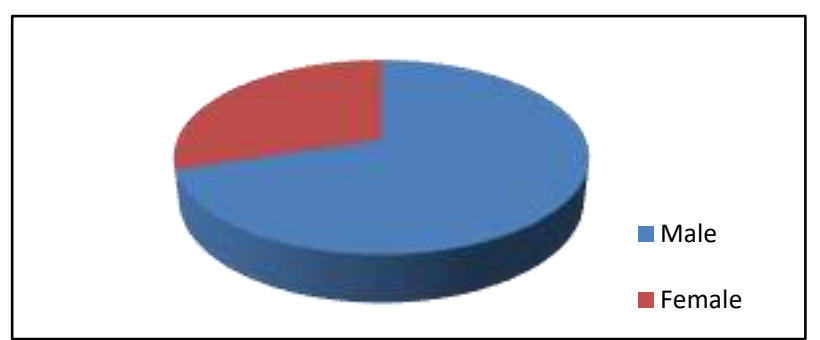

Figure 13: Gender prevalence of AC joint injury.

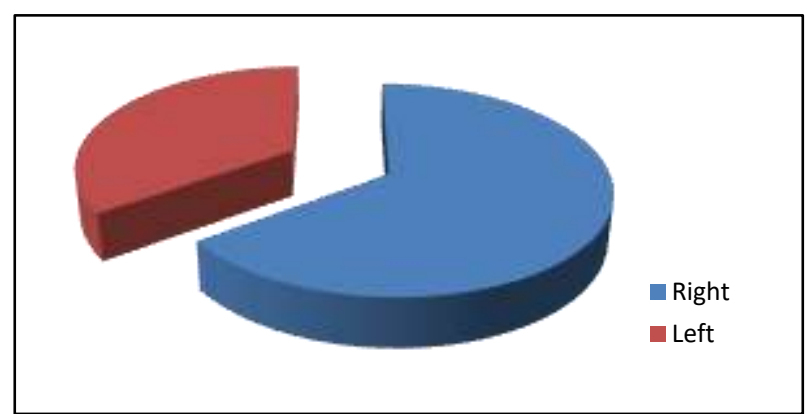

Figure 14: Side predominance of injury. 
All patients were given passive ROM exercise in immediately post-operative period. Active assisted movement started after 3 weeks. At 6 weeks almost all patient develops full ROM except one patient with type 2 Diabetes mellitus (DM) have restricted abduction and internal rotation. Deltoid and rotator cuff strength was measured as per the oxford scale, with 5 of 5 indicating normal strength. Disability of arm, shoulder, hand questionaries' (DASH) done in all 20 patients. Results were tabulated as good (score 0-5), fair (score 5-20), average ( score $>20$ ).

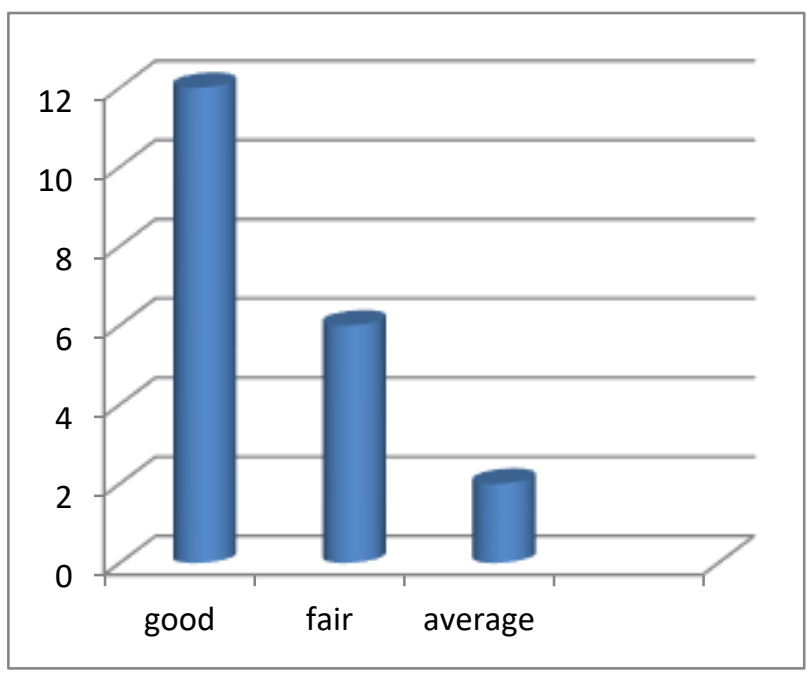

Figure 15: Result of DASH score.

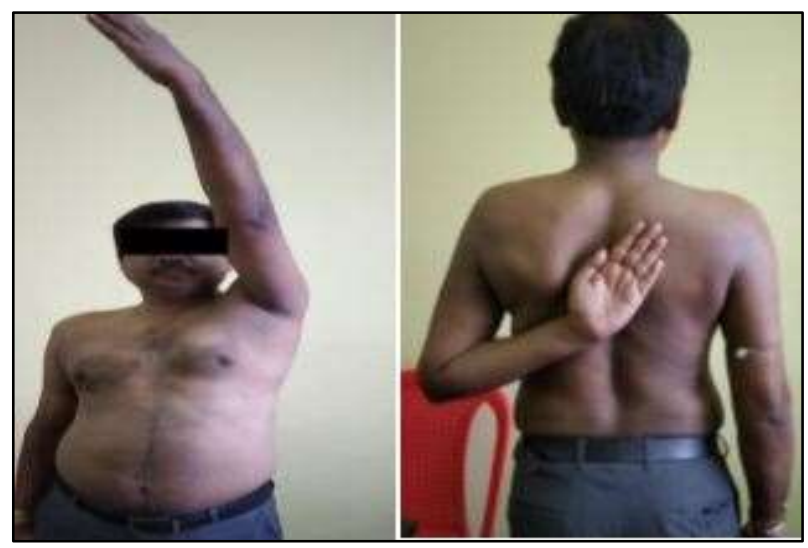

Figure 16: In periodic follow up patient.

AC joint injury is common in young sports individual. Aim of the treatment shoulder give pain free early movement of shoulder, return to sports activities including weight lifting and throwing with preferable no need for subsequent surgeries. Internal brace technique reduces the joint enough to heal native $\mathrm{CC}$ ligamnet. ${ }^{9}$ In periodic follow up patients having less pain, more than $60 \%$ patients having good to excellent results in DASH score, patients having good muscle power and coordination.

Similar study shows internal brace technique performed on type IV and V AC separations results in full return of range of motion and strength, and excellent patient-reported outcomes with no reoperations. Radiographic reduction was maintained in the coronal and sagittal planes. The internal splint technique may be a treatment option for acute treatment of type IV and V AC separations. ${ }^{13}$

\section{CONCLUSION}

Operative treatment with anatomical reduction and fixation by internal brace technique has very good outcome for Rockwood type IV-VI AC separation. This mini open technique has less chance post-operative arthrofibrosis and overall complication rate. So, it may be considered as gold standard for dislocated AC joint injury.

Funding: No funding sources

Conflict of interest: None declared

Ethical approval: Not required

\section{REFERENCES}

1. Willimon SC, Gaskill TR, Millet PJ. Acromioclavicular joint injuries: anatomy, diagnosis and treatment. Phys Sportsmed. 2011;39(1):116-22.

2. Rockwood CJ, Williams G, Young D. Disorders of the Acromioclavicular joint. In: Rockwood CJ, Matsen FA III, eds. The Shoulder. 2nd edition. Philadelphia, PA: WB Saunders; 1998: 483-553.

3. Joukainen A, Kroger H, Niemitukia L, Makela EA, Vaatainen U. Results of operative and nonoperative treatment of Rockwood types III and V acromioclavicular joint dislocation: a prospective, randomized trial with an 18- to 20-year follow up. Orthop J Sports 2014;2(12):2325967114560130.

4. Metzlaff S, Rosslenbroich S, Forkel PH. Surgical treatment of acute acromioclavicular joint dislocations: hook plate versus minimally invasive reconstruction. Knee Surg Sports Traumatol Arthrosc. 2016;24(6):1972-8.

5. Martetschlager F, Horan MP, Warth RJ, Millett PJ. Complications after anatomic fixation and reconstruction of the coracoclavicular ligaments. Am J Sports Med. 2013;41:2896-903.

6. Scheibel M, Droschel S, Gerhardt C, Kraus N. Arthroscopically assisted stabilization of acute highgrade acromioclavicular joint separations. Am J Sports Med. 2011;39:1507-16.

7. Larsen E, Bjerg-Nielsen A, Christensen P. Conservative or surgical treatment of acromioclavicular dislocation. J Bone Joint Surg Am. 1986;68:552-5.

8. Scheibel M, Dröschel S, Gerhardt C, Kraus N. Arthroscopically assisted stabilization of acute highgrade acromioclavicular joint separations. Am J Sports Med. 2011;39(7):1507-16.

9. Wylie JD, Johnson JD, DiVenere J, Mazzocca AD. Shoulder acromioclavicular and coracoclavicular ligament injuries: Common problems and solutions. Clin Sports Med. 2018;37:197-207. 
10. Beitzel K, Obopilwe E, Chowaniec DM. Biomechanical comparison of arthroscopic repairs for Acromioclavicular joint instability: Suture button systems without biological augmentation. Am J Sports Med. 2011;39:2218-25.

11. Eschler A, Gradl G, Gierer P, Mittlmeier T, Beck M. Hook plate fixation for acromioclavicular joint separations restores coracoclavicular distance more accurately than PDS augmentation, however presents with a high rate of acromial osteolysis. Arch Orthop Trauma Surg. 2012;132(1):33-9.

12. Baker JE, Gregg NT, Young DC, Owen JR, Wayne JS. A cadaveric study examining acromioclavicular joint congruity after different methods of coracoclavicular loop repair. J Shoulder Elbow Surg. 2003;12(6):595-8.

13. LaMartina JA, Lau BC, Miller L, Salesky MA. Acute Fixation of Type IV and Acromioclavicular Separations -An Internal Splint Technique- Orthop J Sport Med. 2018;6(7):2325967118783752.

Cite this article as: Ganguli R. Operative fixation of type IV-VI acromioclavicular joint separation: an internal splint technique. Int J Res Orthop 2020;6:1291-6. 